\title{
Viability of Bacillus subtilis Cells in Airborne Bioaerosols on Face Masks
}

\author{
Eun-Hee Lee ${ }^{1, *}$, Yunsoo Chang ${ }^{1(D)}$ and Seung-Woo Lee ${ }^{2,3,4}$ \\ 1 Department of Microbiology, Pusan National University, 2 Busandaehak-ro 63 beon-gil, \\ Geumjeong-gu, Busan 46241, Korea; 08149@naver.com \\ 2 Department of Fine Chemistry, Seoul National University of Science and Technology, Seoul 01811, Korea; \\ swlee@seoultech.ac.kr \\ 3 Department of Nano Bio Engineering, Seoul National University of Science and Technology, \\ Seoul 01811, Korea \\ 4 Center for Functional Biomaterials, Seoul National University of Science and Technology, Seoul 01811, Korea \\ * Correspondence: leeeh@pusan.ac.kr
}

Citation: Lee, E.-H.; Chang, Y.; Lee, S.-W. Viability of Bacillus subtilis Cells in Airborne Bioaerosols on Face Masks. Atmosphere 2021, 12, 1496. https://doi.org/10.3390/ atmos12111496

Academic Editor: Salvatore Romano

Received: 28 September 2021

Accepted: 10 November 2021

Published: 12 November 2021

Publisher's Note: MDPI stays neutral with regard to jurisdictional claims in published maps and institutional affiliations.

Copyright: (c) 2021 by the authors. Licensee MDPI, Basel, Switzerland. This article is an open access article distributed under the terms and conditions of the Creative Commons Attribution (CC BY) license (https:// creativecommons.org/licenses/by/ $4.0 /)$.

\begin{abstract}
The coronavirus disease 2019 (COVID-19) pandemic is a general health crisis and has irreversible impacts on human societies. Globally, all people are at risk of being exposed to the novel coronavirus through transmission of airborne bioaerosols. Public health actions, such as wearing a mask, are highly recommended to reduce the transmission of infectious diseases. The appropriate use of masks is necessary for effectively preventing the transmission of airborne bioaerosols. The World Health Organization (WHO) suggests washing fabric masks or throwing away disposable masks after they are used. However, people often use masks more than once without washing or disposing them. The prolonged use of a single mask might—as a result of the user habitually touching the maskpromote the spread of pathogens from airborne bioaerosols that have accumulated on the mask. Therefore, it is necessary to evaluate how long the living components of bioaerosols can be viable on the masks. Here, we evaluated the viability of airborne Bacillus subtilis (B. subtilis) in bioaerosols filtered on woven and anti-droplet (non-woven) face masks. As a simulation of being simultaneously exposed to sand dust and bioaerosols, the viability rates of bioaerosols that had accumulated on masks were also tested against fine dust and airborne droplets containing bacteria. The bioaerosols survived on the masks immediately after the masks were used to filter the bioaerosols, and the bacteria significantly proliferated after one day of storage. Thereafter, the number of viable cells in the filtered bioaerosols gradually decreased over time, and the viability of B. subtilis in bioaerosols on the masks varied, depending on the mask material used (woven or non-woven). Despite the reduction in viability, bioaerosols containing living components were still found in both woven and anti-droplet masks even after six days of storage and it took nine days not to have found them on masks. The number of viable cells in bioaerosols on masks significantly decreased upon exposure of the masks to fine dust. The results of this study should provide useful information on how to appropriately use masks to increase their duration of effectiveness against bioaerosols.
\end{abstract}

Keywords: woven; fabric; anti-droplet; facepiece; bioaerosol; survival

\section{Introduction}

Coronavirus disease 2019 (COVID-19), caused by severe acute respiratory syndrome coronavirus 2 (SARS-CoV-2), has spread around the world since the first case was identified in December 2019 [1]. COVID-19 is an ongoing global pandemic and over 4.57 million deaths among 221 million confirmed cases have been reported to the World Health Organization (WHO) as of 7 September 2021 [2].

The SARS-CoV-2 virus causing COVID-19 is mainly transmitted from an infected person to another person in close contact. The infected people release respiratory droplets and aerosol particles when they cough, sneeze, speak, sing, or breathe. The respiratory 
fluids carry virus particles and transmit the particles to other people primarily through direct contact with the virus-containing droplets, but also to some extent as a result of contact with surfaces having the virus on them [3,4]. To prevent airborne transmission of COVID-19 between people, the WHO has highly recommended public physical distancing, wearing a mask, cleaning hands, keeping rooms well ventilated, and obtaining a vaccine when eligible [5,6]. A combination of public health actions is necessary to reduce the spread of infectious diseases such as COVID-19.

Personal protective equipment, such as a facepiece, provides protection from infectious diseases by preventing the transmission of respiratory fluids to mucous membranes in the mouth and nose [7]. Many studies have documented the filtration performances of facepieces against bioaerosols [8-12]. The filtration efficiency levels of the masks against bioaerosols have been found to vary, depending on the material the masks were made of (cotton, gauze, or polypropylene). Our previous study showed relatively low average filtration efficiency levels of $68.3-76.5 \%$ displayed by woven masks against airborne bacteria-containing droplets [8]. In contrast, non-woven masks, specifically anti-droplet, Korea filter (KF)80, and KF94 masks, achieved high average filtration efficiency levels greater than $90 \%$ against the airborne bacteria-containing droplets. Despite the differences in filtration performance between the different types of masks, the results clearly indicated that using any of these masks can, at least to some extent, reduce the transmission of airborne droplets.

The appropriate use of masks is of great importance to make them effective at preventing the transmission of bioaerosols. The WHO indicated after how long of a use the masks should be washed or disposed of non-woven ones [13]. Despite these recommendations, however, users of masks often wear them more than once without washing or disposing them. More importantly, they frequently_perhaps out of habit—use their hands to touch the masks they are wearing [14]. Such touching of the surfaces of masks contaminated with bioaerosols can lead to the transmission of infectious diseases [15]. In this regard, it is necessary to evaluate how long the living components of bioaerosols can survive and be viable on masks exposed to them.

In this study, we evaluated the viability rates of the living components of bioaerosols filtered on the masks. Two different masks commercially available in Korea, specifically woven and anti-droplet masks, were chosen for these viability experiments. Using airborne droplets containing bacteria, bioaerosols were generated and made to contact the masks with a laboratory-scale filtration system. The filtered bioaerosols on the masks were cultured to measure the viability rates of the bacteria in these bioaerosols. Additionally, the viability levels of the living components in the bioaerosols were also determined in experiments in which the masks were also exposed to fine dust as a simulation of the real-life exposures to sand dust and bioaerosols.

\section{Materials and Methods}

\subsection{Filtration System Used to Evaluate the Viability of Bioaerosol Bacteria}

A filtration system was designed to evaluate the viability of bioaerosol bacteria. This system consisted of an inlet, filtration module, and outlet (Figure 1a). The inlet port was connected to the filtration module, which was composed of two custom-made acrylic cylinders $(8 \mathrm{~cm} \times 10 \mathrm{~cm}$, diameter $\times$ length). A face mask was placed between this cylinder and an another identically-shaped cylinder and the cylinders were tightly closed to prevent leakage during operation. The tested face masks, specifically woven and anti-droplet masks, were commercially available in Korea with high market shares. The woven mask has a cup-shaped design with flexibility and air permeability. The anti-droplet mask has a planar design with effective prevention against droplets. The outlet port was connected to a vacuum pump, and thus, airborne droplets containing bacteria were introduced to the mask from the chamber. The composition of the filtration system was previously described in detail in Lee et al. (2021) [8]. 
(a)

(a) Airborne bacteria

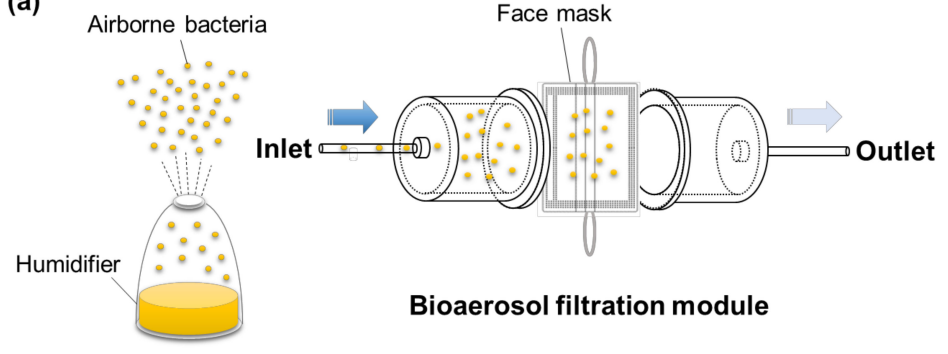

(b)

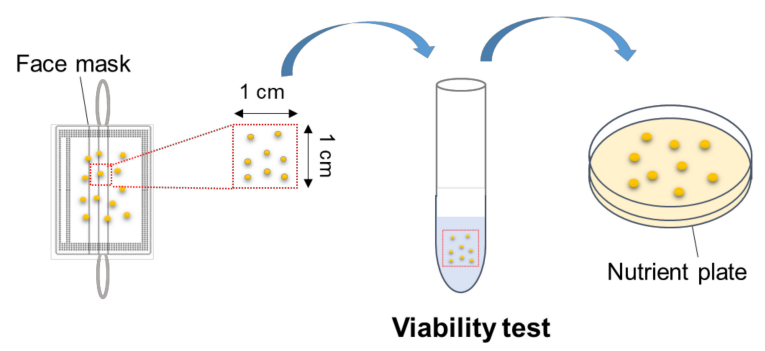

Figure 1. (a) Schematic illustration of a laboratory-scale system suitable for filtering airborne bioaerosols using face masks. (b) Experimental procedure used to perform viability tests for bioaerosols on face masks.

\subsection{Use of Face Masks to Filter Airborne Bacteria-Containing Droplets}

The bacterium Bacillus subtilis (B. subtilis, FBCC-B1550, Nakdonggang National Institute of Biological Resources, Sangju, Gyeongsangbuk-do, Korea) was used for generating airborne bioaerosols. B. subtilis is a Gram-positive, spore-forming organism that can survive in the form of bacterial cells and spores in the air and is found in indoor and outdoor environments [16,17]. The B. subtilis was cultured at $30{ }^{\circ} \mathrm{C}$ in a nutrient broth (MBcell, KisanBio Co., Seoul, Korea) that was subjected to agitation at $180 \mathrm{rpm}$ (revolutions per minute) for $16 \mathrm{~h}$. The resulting culture broth was subjected to centrifugation at $4424 \times g$ for $10 \mathrm{~min}$, and the resulting pelleted B. subtilis cells were washed twice with a solution of phosphate-buffered saline (PBS, pH 7.0, Sigma-Aldrich, St. Louis, MO, USA). The $B$. subtilis cells were then diluted to a concentration of $1.5 \pm 0.4 \times 10^{8}$ colony forming units (CFU) $/ \mathrm{mL}$, and the suspension was loaded into an atomizer (DP3355-UH, Yangil Co., Hwaseong, Gyeonggi-do, Korea). Bioaerosols of B. subtilis cells were generated in a chamber $(100 \mathrm{~cm} \times 60 \mathrm{~cm} \times 120 \mathrm{~cm}$, width $\times$ length $\times$ height $)$ by atomizing $5 \mathrm{~mL}$ of a washed culture broth. Air-containing bioaerosols of $B$. subtilis cells were introduced into the face mask-equipped filtration module at a flow rate of $30 \mathrm{~L} / \mathrm{min}$ by using a vacuum pump. The filtration system was continuously operated for $3 \mathrm{~min}$. Each of the bioaerosol filtration experiments was performed in triplicate.

\subsection{Effects of Particulate Matters (PMs) on the Viability of Bioaerosol Bacteria on the Masks}

Particulate matters (PMs) were simultaneously produced with bioaerosols by fuming incense (Perak, Malaysia) into the chamber. Air containing bioaerosols and PMs were introduced into the filtration module as described above. The filtration system was continuously operated for $3 \mathrm{~min}$. The concentrations of PM1.0 (particles with dimensions $<1 \mu \mathrm{m}$ ), PM2.5 $(<2.5 \mu \mathrm{m})$, and PM10 $(<10 \mu \mathrm{m})$ particles in the inlet and outlet were measured every second using PM detectors (PM2008M, Cubic Sensor and Instrument Co., Ltd., Wuhan, China). The filtration efficiency of each mask against PM was determined using the equation

$$
\text { Filtration efficiency against particulate matter }(\%)=\left(1-\frac{C_{\text {outlet }}}{C_{\text {inlet }}}\right) \times 100 \text {, }
$$

where $C_{\text {inlet }}$ and $C_{\text {outlet }}$ represent PM concentrations $\left(\mu \mathrm{g} / \mathrm{m}_{\text {air }}{ }^{3}\right)$ at the inlet and outlet, respectively. Each of the experiments was performed in triplicate. 


\subsection{Viability Tests for Airborne B. subtilis in Bioaerosols Filtered on the Masks}

Three different locations (upper, middle, and bottom spots) of each mask were selected for measuring the viability of $B$. subtilis in bioaerosols. Each location of the face mask was cut into $1 \mathrm{~cm}^{2}$ pieces and stored at ambient temperature prior to performing experiments for viability. The living components (i.e., bacteria) of the bioaerosols filtered on the piece of mask were cultured immediately after the mask was used to filter the sprayed bioaerosols (denoted as "day 0 "), at 1 day after the mask was used ("day 1"), and at days 2, 3, 6, and 9 (Figure 1b). After exposure to the bioaerosols, the masks were stored in a plastic bag at ambient temperature prior to analysis. Briefly, each mask piece was transferred to a respective $50 \mathrm{~mL}$ tube containing $10 \mathrm{~mL}$ of a solution of $0.9 \%$ sodium chloride $(\mathrm{NaCl}$, Samchun Chemical Co., Ltd., Pyeongtaek, Gyeonggi-do, Korea). The tube was incubated at $30^{\circ} \mathrm{C}$ with shaking at $180 \mathrm{rpm}$ for $1 \mathrm{~h}$ to detach the filtered bioaerosols from the mask. The suspension was serially diluted using a $0.9 \% \mathrm{NaCl}$ solution. Aliquots of the suspension were spread on nutrient agar plates (MBcell, KisanBio Co.), and the plates were statically incubated at $30^{\circ} \mathrm{C}$ for $16 \mathrm{~h}$. After this incubation, colonies grown on the plates were counted and photographed, and the viability levels of the bacteria in the filtered bioaerosols were determined by measuring the CFUs of the plates initially $\left(\mathrm{CFU}_{0}\right)$ and immediately after a specific amount of time (CFUt), namely 0, 1, 2, 3, 6, and 9 days, and using the equation

$$
\text { Viability }(\%)=\left(\frac{C F U_{t}}{C F U_{0}}\right) \times 100
$$

The experiments were carried out in triplicate.

\section{Results and Discussion}

\subsection{Viability of B. subtilis from Airborne Bioaerosols Filtered on Face Masks}

As a simulation of coughing, speaking, and sneezing conditions, airborne droplets containing B. subtilis cells were sprayed into the face masks through a filtration system, and the longevity of bacteria on the masks was measured by culturing $B$. subtilis in bioaerosol (Figure 1). The numbers of viable B. subtilis cells obtained from the masks immediately after they were exposed to the sprayed bioaerosols and after culturing (denoted as "day 0 ") were in the range $1.8-8.3 \times 10^{3} \mathrm{CFU} / \mathrm{cm}^{2}$; with the larger number observed, at day 0 , for the anti-droplet masks than for the woven masks (Figures 2a and 3a).
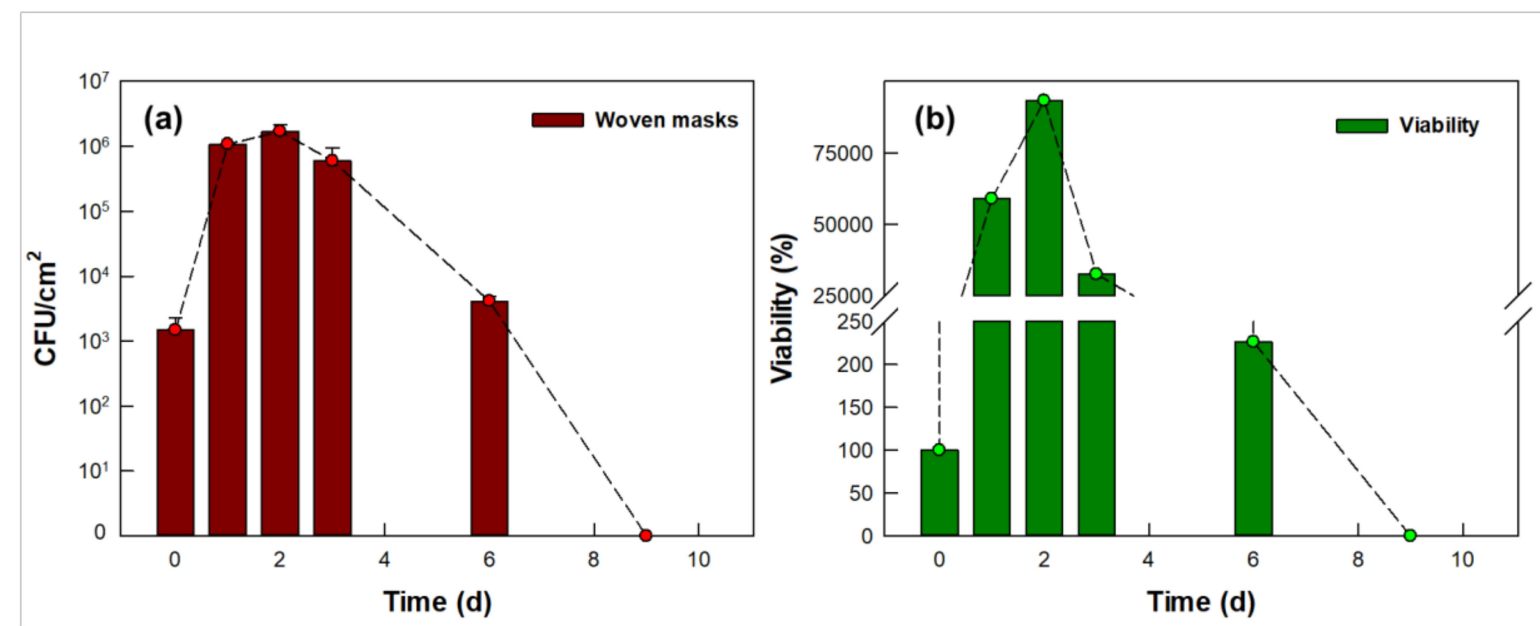

Figure 2. Viability levels of B. subtilis from airborne bioaerosols filtered by a woven face mask. (a) Colony forming unit $(\mathrm{CFU}) / \mathrm{cm}^{2}$ values and (b) viability rates of the B. subtilis airborne bioaerosols. Error bars represent standard deviation of the data $(n=9)$. The dashed line shows a trend of each result. 

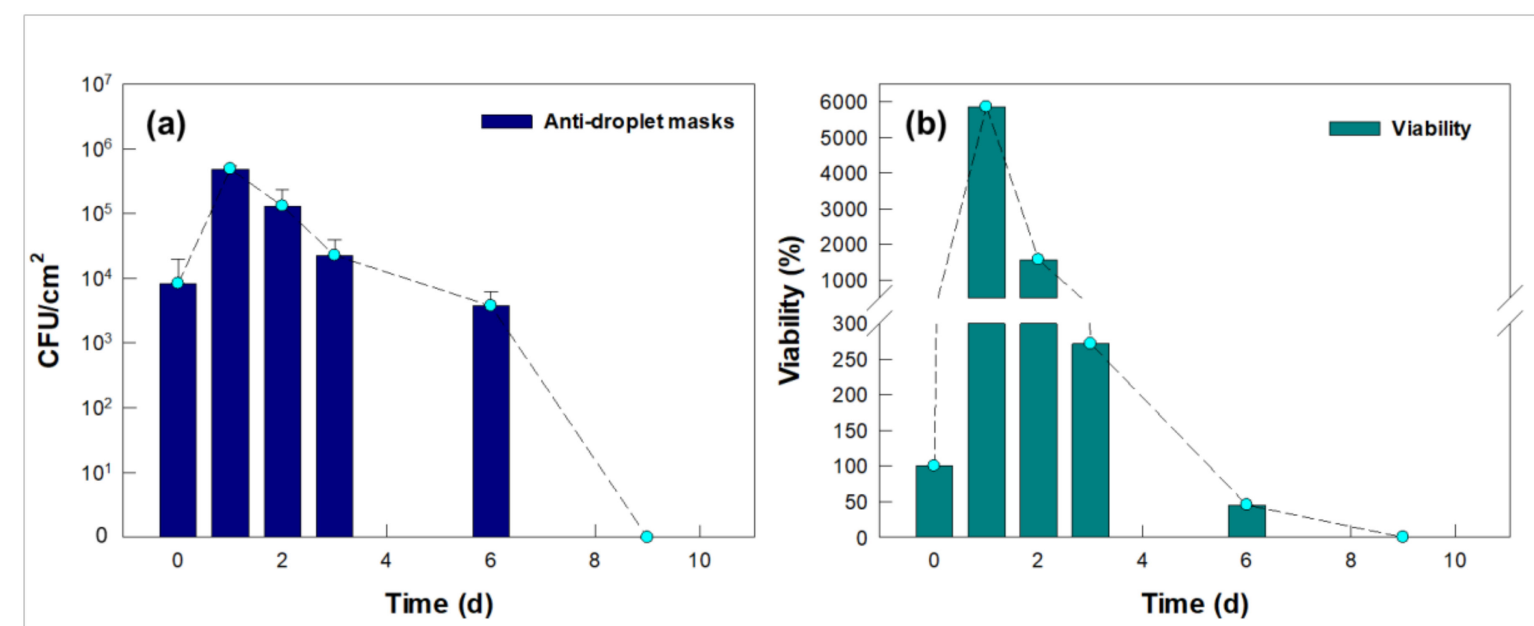

Figure 3. Viability levels of B. subtilis from airborne bioaerosols filtered by an anti-droplet face mask. (a) Colony forming unit $(\mathrm{CFU}) / \mathrm{cm}^{2}$ values and (b) viability rates of the $B$. subtilis airborne bioaerosols. Error bars represent standard deviation of the data $(n=9)$. The dashed line shows a trend of each result.

The filtered viable airborne bioaerosols significantly proliferated in both woven and anti-droplet masks after 1 day of storage (day 1$)(p<0.05$, determined by t-test using SigmaPlot program, Systat Software, Inc., San Jose, CA, USA, Figures 2a and 3a). Numerous colonies were found in the agar plates at day 1 (Figure 4). The number of viable B. subtilis cells from the bioaerosol-exposed masks increased 590-fold from $1.8 \times 10^{3}$ initially (day 0 ) to $1.1 \times 10^{6} \mathrm{CFU} / \mathrm{cm}^{2}$ at day 1 when woven masks were tested, while at the same time span it increased 59-fold from $8.3 \times 10^{3}$ to $4.9 \times 10^{5} \mathrm{CFU} / \mathrm{cm}^{2}$ when anti-droplet masks were used. From day 1 to day 2, this number increased further to $1.7 \times 10^{6} \mathrm{CFU} / \mathrm{cm}^{2}$ for the woven masks (Figures 2a and 4a)-but decreased, to $1.3 \times 10^{5} \mathrm{CFU} / \mathrm{cm}^{2}$ for the anti-droplet masks (Figures $3 \mathrm{a}$ and $4 \mathrm{~b}$ ).

From day 2 to day 3 , the number of viable B. subtilis cells from the woven masks slightly decreased to $6.0 \times 10^{5} \mathrm{CFU} / \mathrm{cm}^{2}$, but was still $32,630 \%$ that of the initial number of cells (Figure 2). From day 3 to day 6 , however, the number of viable $B$. subtilis cells obtained from the woven masks significantly decreased $(p<0.05)$, to $4.1 \times 10^{3} \mathrm{CFU} / \mathrm{cm}^{2}$, and the corresponding viability was determined to be only $226 \%$. No colonies were observed to have grown on agar plates for the woven masks treated after 9 days of storage after the filtration (Figure $4 \mathrm{a}$ ), as the viability of $B$. subtilis cells in bioaerosols decreased to $0 \%$ (Figure 2b).

From day 2 to day 3 , the number of viable $B$. subtilis cells from the anti-droplet masks decreased to $2.3 \times 10^{4} \mathrm{CFU} / \mathrm{cm}^{2}$, and the viability rate was $271 \%$. In addition, the number of colonies grown on the agar plates was significantly reduced at day 6 (Figures 3 and $4 b$ ): by this amount of time after storage, the number of viable $B$. subtilis cells on the anti-droplet masks decreased considerably to $3.8 \times 10^{3} \mathrm{CFU} / \mathrm{cm}^{2}$ and the viability appeared to be only $45 \%(p<0.05$, Figures 3 and 4$)$. Moreover, at day 9 , no colonies were observed on the agar plates (Figure $4 b$ ): by this time, the viability of cells in bioaerosols corresponded to $0 \%$ (Figure 3b).

The greater number of initial viable airborne bioaerosols on anti-droplet masks than those on woven masks at day 0 was attributed to the differences of filtration performance between woven and anti-droplet masks. Our previous study reported that non-woven face masks achieved a filtering performance superior to that of woven masks against airborne droplets containing bacteria [8]. The filtration efficiency of the anti-droplet masks appeared to be $91.6-97.0 \%$ against airborne droplets containing B. subtilis cells, whereas the corresponding filtration efficiency of the woven masks was indicated to be only $68.3-76.5 \%$ [8]. Therefore, the greater filtration efficiency of the anti-droplet masks was concluded to lead to a higher accumulation of bioaerosols on their filters. 

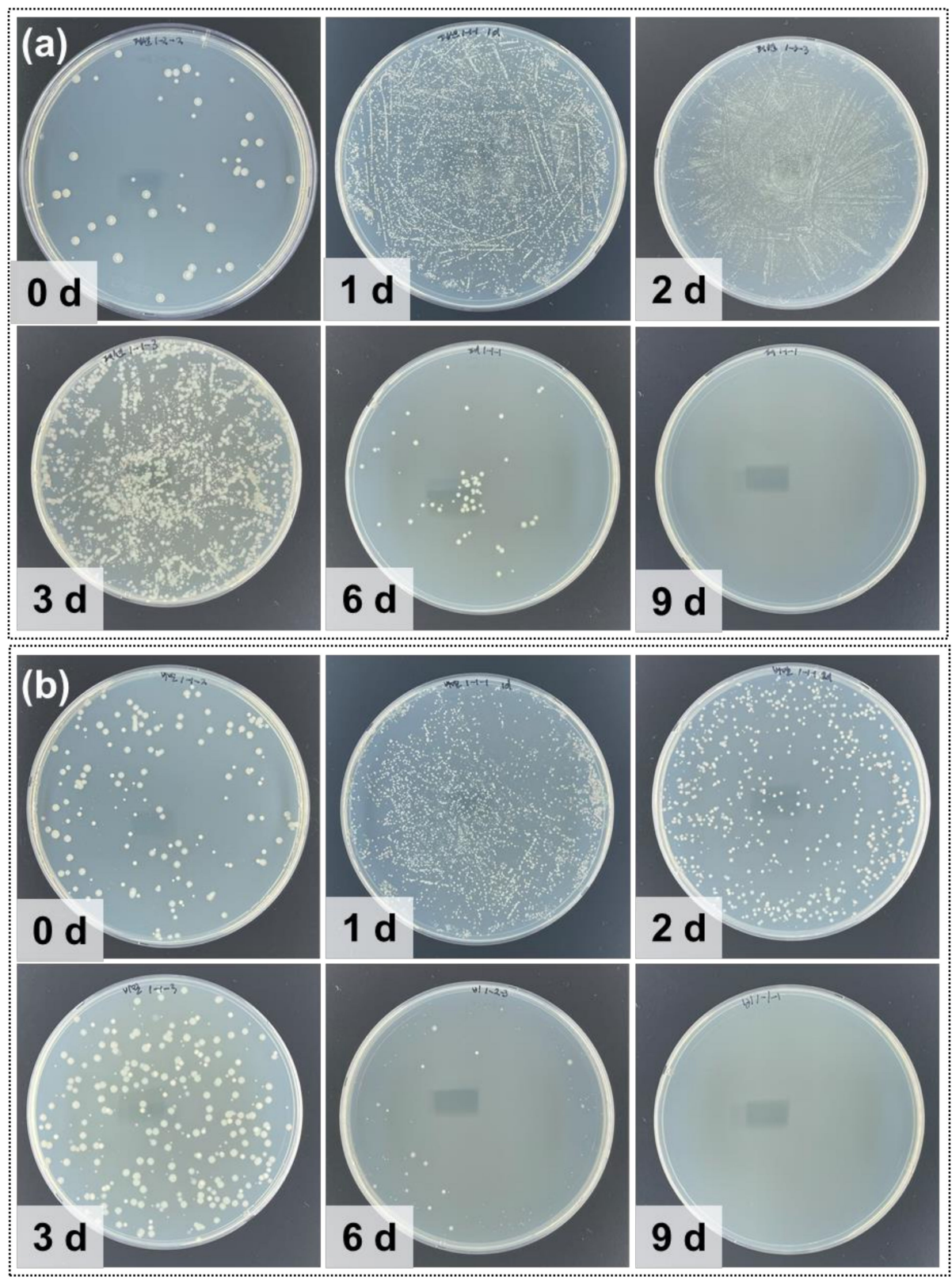

Figure 4. Photographs of B. subtilis grown on agar plates after the B. subtilis-containing bioaerosols were filtered by (a) woven and (b) anti-droplet masks.

Although the initial numbers of viable cells of airborne bioaerosols at day 0 were lower when the bioaerosols were filtered using woven masks than when they were filtered using anti-droplet masks, the proliferation of these cells was much greater on woven masks than those on anti-droplet masks (at day 1, Figures 2-4). Moreover, the growth of cells from airborne $B$. subtilis bioaerosols filtered using the woven masks continued for 2 days, while a decrease in the number of viable cells from day 1 to day 2 was found for the anti-droplet masks. The reproduction of the cells of filtered bioaerosols seemed to be related to the properties of the masks. The woven masks got soaked with the sprayed airborne droplets containing bacteria-but the anti-droplet masks, being hydrophobic, were incapable of absorbing the airborne droplets. The hydrophilicity of a mask might affect the growth of cells in filtered airborne B. subtilis bioaerosols on masks. The results indicated that the woven masks tested provided more suitable conditions for growing cells from filtered B. subtilis bioaerosols than did the anti-droplet masks. 
After rapid proliferation of the bacteria from the airborne B. subtilis bioaerosols, the viability of the bioaerosols gradually decreased during the 9 days of mask storage, but the degree of the reduction in the viability was dependent on the mask type. The anti-droplet masks showed greater reduction in the numbers of viable cells from airborne B. subtilis bioaerosols than did the woven masks (Figures 2-4). Nonetheless, no viable cells in the bioaerosols were found in both woven and anti-droplet masks after nine days of storage.

Although the viabilities of filtered airborne B. subtilis bioaerosols on anti-droplet masks decreased more rapidly than did those on woven masks, both the woven and antidroplet masks did not display sufficiently satisfactory antibacterial properties to prevent the filtered bioaerosols from having viable cells. The living components of bioaerosols were still found on masks even 6 days after the masks were used to filter the bioaerosols. The results revealed the ability of the bacteria from the filtered airborne B. subtilis bioaerosols to survive and be viable on the masks for a quite extended period of time, in fact for longer than we had originally expected. Spores help bacteria to endure harsh conditions, such as solar radiation, high temperature, dryness, and insufficient nutrients $[18,19]$. In this regard, the spore-forming properties of the B. subtilis used in this study may have indeed enabled the bacteria to be resistant to drying out and to survive on the masks during the 6 days of storage.

Jeong et al. (2021) determined that the survival rates of Staphylococcus epidermidis in bioaerosols from facepieces and surgical mask filters to be 13\% [20]. Lin et al. (2017) also reported that the viability of airborne $B$. subtilis spores filtered on facepieces and surgical masks increased by over $100 \%$ when they were stored at $37^{\circ} \mathrm{C}$ with a relative humidity of $95 \%$ for $24 \mathrm{~h}$, i.e., in conditions similar to those of a used mask [21]. The results suggested that storage of the worn masks at ambient temperature is not a good strategy for reducing the viability of bacteria in filtered bioaerosols, and thus, an appropriate method is required for reusing the masks.

Our study indicated that more airborne bioaerosols penetrated through the woven masks tested and would thus directly be able to enter the respiratory tract than were trapped by the masks. On the other hand, more such bioaerosols were trapped by the anti-droplet masks than passed through them due to the great filtration performance of these masks against airborne droplets containing bacteria. Nevertheless, wearing masks even with high filtration performance may also allow for the transmission of respiratory disease if these masks are inappropriately used, such as when their surfaces are touched by the hands of the user [20-22]. Therefore, misusing masks poses risks to health as a result of bioaerosols passing through them or from the survival of living components on the masks, or from both.

\subsection{Effects of Particulate Matters (PMs) on Viability of Bacteria in Airborne Bioaerosols Filtered on Masks}

The viability of $B$. subtilis in airborne bioaerosols filtered on face masks was evaluated upon co-exposure of the masks to PMs (Figures 5 and 6). The living components of the bioaerosols were only found in two spots of the anti-droplet masks among the nine different spots tested (three locations $\times$ three masks), while they were detected in six spots of the woven masks. Interestingly, the number of viable cells of the bioaerosols were substantially reduced from $1.8 \times 10^{3}$ to $3.3 \times 10^{2} \mathrm{CFU} / \mathrm{cm}^{2}$ on woven masks right after exposure to PMs ( $p<0.05$, at day 0), compared to the negative control (exposure to bioaerosols only, Figures 2 and 4). The decrease in this number was particularly significant when anti-droplet masks were used as the filter, as this decrease was from $8.3 \times 10^{3}$ to $1 \times 10^{2} \mathrm{CFU} / \mathrm{cm}^{2}$ $(p<0.05$, Figures 3 and $5 b)$. At day 1 and thereafter through day 9 , living components in bioaerosols were found neither in woven nor anti-droplet masks (Figures 5 and 6). 

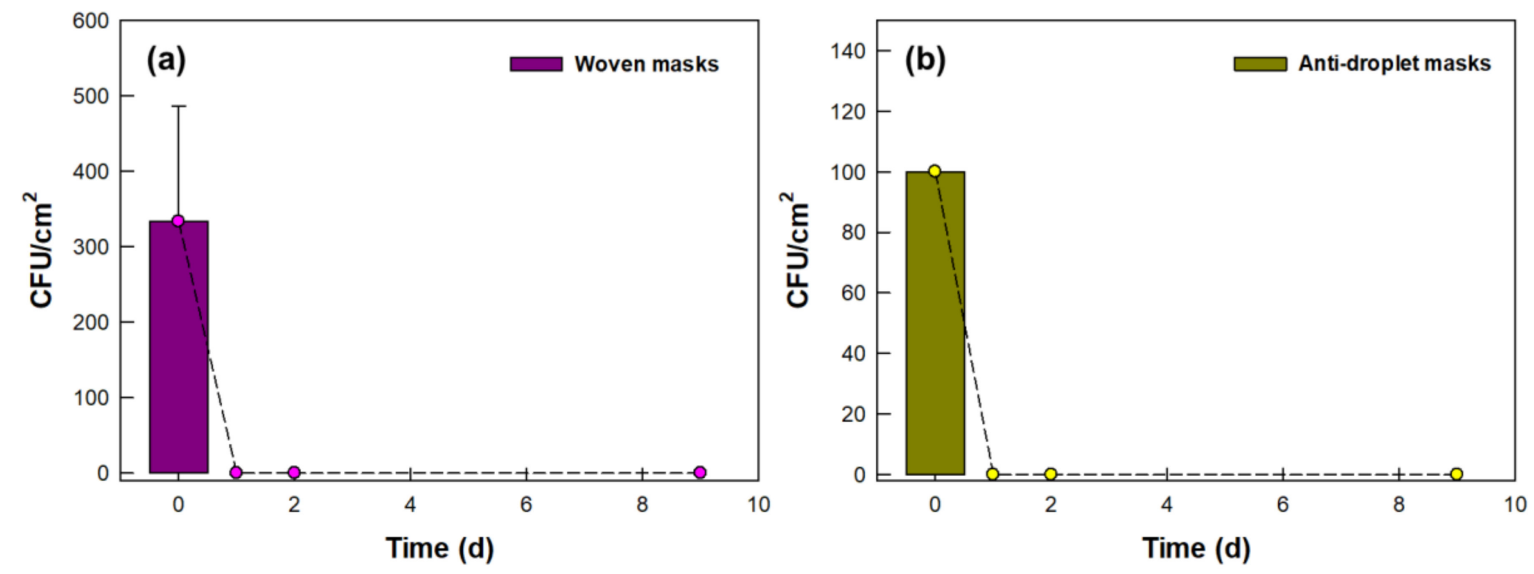

Figure 5. Colony forming unit (CFU) $/ \mathrm{cm}^{2}$ values of airborne B. subtilis from bioaerosols on (a) woven and (b) anti-droplet face masks after these masks were used to filter particulate matters (PMs) and airborne droplets containing bacteria. Error bars represent standard deviation of the data $(n=9)$. The dashed line shows a trend of each result.

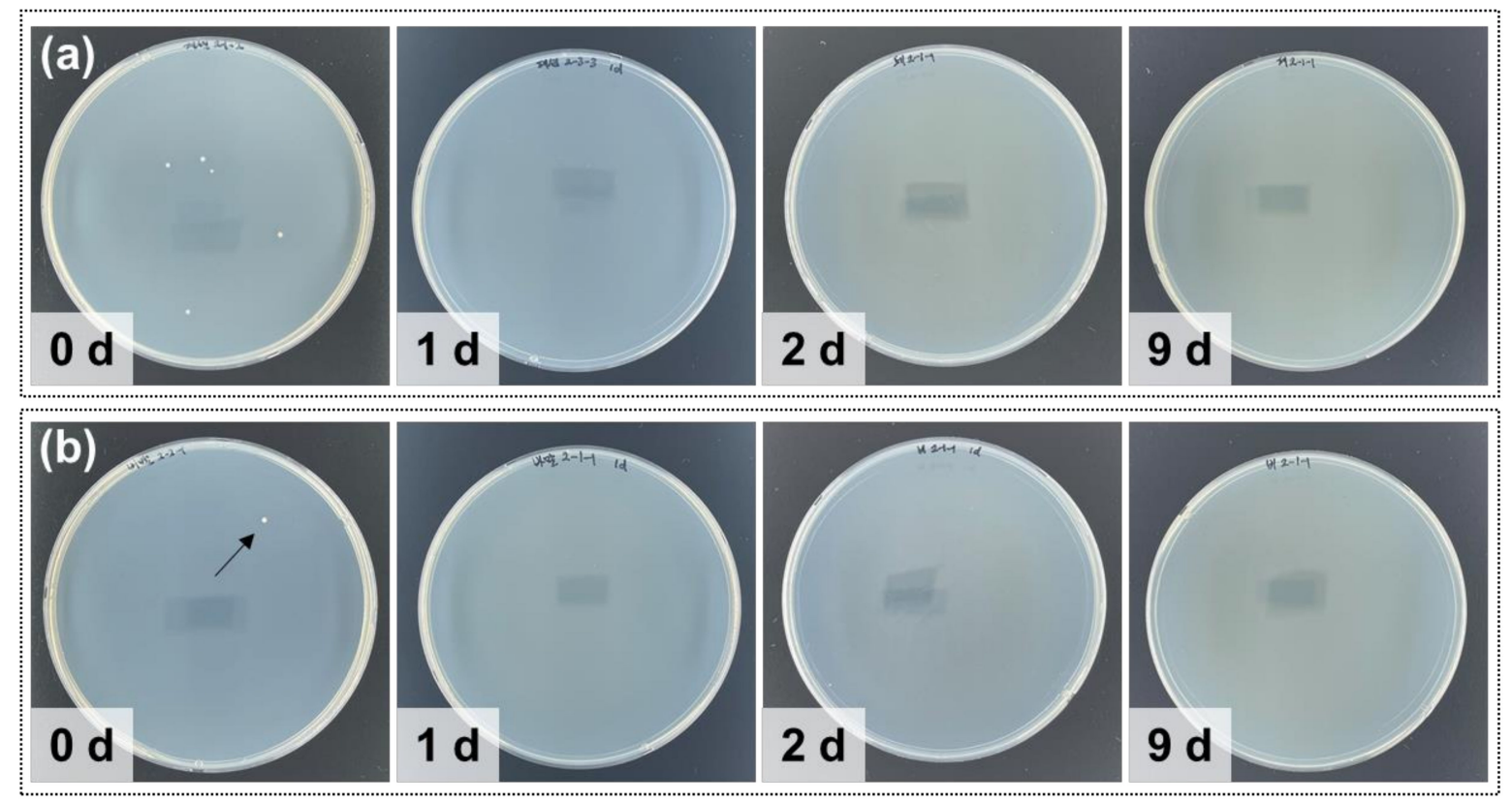

Figure 6. Photographs of airborne B. subtilis bioaerosols grown on agar plates after being derived from (a) woven and (b) anti-droplet masks that were used as filters of both particulate matters (PMs) and airborne droplets containing bacteria. The arrow marks a colony of airborne $B$. subtilis cells grown on the plate.

The results indicated that the PMs significantly decreased the viability of B. subtilis in bioaerosols. Similarly, Noda et al. (2019) found that desert sand dust from Mongolia decreased the viability of Escherichia coli DH5- $\alpha$ in bioaerosols [23]. Hara and Zhang (2012) reported that the viability of bacteria was much less in days with dusty air than in nondusty days [24]. Gong et al. (2020) also documented that the bacterial viability showed a negative correlation with PM2.5 and PM10 [25]. Note that woven masks recorded low average filtration efficiencies against PMs, specifically $63.2 \pm 6.3 \%$ against PM1.0, $63.5 \pm 0.9 \%$ against PM2.5, and 57.8 $\pm 6.8 \%$ against PM10. Anti-droplet masks achieved great filtration efficiencies of $80.6 \pm 1.0 \%$ against PM1.0, $80.3 \pm 0.8 \%$ against PM2.5, and $79.2 \pm 0.6 \%$ against PM10. The differences of filtration performance between woven and anti-droplet masks against PMs might influence the viability of filtered airborne B. subtilis 
bioaerosols - with fewer colonies found on anti-droplet masks than on woven masks due to their greater accumulation of PMs on the masks as a result of filtration.

While Bacillus bacteria are well known to form airborne bioaerosols, other airborne microbes have been identified as well [26-29]. The viability properties of other bioaerosols may differ from those found in our study, and merit their own investigations to extend our results.

\section{Conclusions}

We evaluated the viability of B. subtilis in airborne bioaerosols filtered on commercially available masks. The airborne bioaerosols were found to be viable on the masks for at least 6 days, regardless of the material the mask was made of (i.e., woven or non-woven polypropylene), indicating the possibility of spreading bioaerosol-derived particles by touching the surfaces of masks, as well as a result of the bioaerosols penetrating through the masks. It needs at least 9 days that the viable cells in filtered airborne bioaerosols are not to be found on masks. The viability levels of the bioaerosol cells were significantly decreased by fine dust: viable cells from bioaerosols were rarely found upon exposure of the masks to both PMs and the bioaerosols, compared to the negative controls in which PMs were not present. This finding indicated that the fine dust has a significant impact on the viability of cells in bioaerosols. A future study will be necessary to further elucidate their inhibitory interactions in detail.

Our results suggested that masks used more than once may serve as fomites transmitting bioaerosols, since bacteria in filtered bioaerosols on masks are viable for a prolonged period of at least 6 days. The appropriate use of masks, including refraining from touching the surfaces of masks contaminated with bioaerosols, would thus be expected to reduce the transmission of airborne droplets and provide effective protection.

Author Contributions: Conceptualization, E.-H.L. and S.-W.L.; Methodology, E.-H.L.; Validation, E.-H.L. and Y.C.; Original Draft Preparation, E.-H.L.; Writing-Review \& Editing, E.-H.L. and S.-W.L. All authors have read and agreed to the published version of the manuscript.

Funding: This study was supported by National Research Foundation of Korea (NRF) grants funded by the Korean government (NRF-2019R1A2C1088541 and NRF-2020R1C1C1005743), and in part funded by the Research Fund Program of Research Institute for Basic Sciences, Pusan National University, Korea, 2020, Project No. RIBS-PNU-2020-002 and by a Pusan National University Research Grant, 2020.

Institutional Review Board Statement: Not applicable.

Informed Consent Statement: Not applicable.

Data Availability Statement: Not applicable.

Conflicts of Interest: The authors declare no conflict of interest.

\section{References}

1. Park, S.H. Personal Protective Equipment for Healthcare Workers during the COVID-19 Pandemic. Infect. Chemother. 2020, 52, 165-182. [CrossRef]

2. W.H.O. WHO Coronavirus Disease (COVID-19) Dashboard (8 September 2021). Available online: https://covid19.who.int/ (accessed on 8 September 2021).

3. Siegel, J.D.; Rhinehart, E.; Jackson, M.; Chiarello, L.; Healthcare infection control practices advisory committee. 2007 Guideline for isolation precautions: Preventing transmission of infectious agents in healthcare settings. Am. J. Infect. Control. 2007, 35, S65-S164. [CrossRef] [PubMed]

4. Otter, J.A.; Donskey, C.; Yezli, S.; Douthwaite, S.; Goldenberg, S.; Weber, D.J. Transmission of SARS and MERS coronaviruses and influenza virus in healthcare settings: The possible role of dry surface contamination. J. Hosp. Infect. 2016, 92, 235-250. [CrossRef] [PubMed]

5. W.H.O. Coronavirus Disease (COVID-19) Advice for the Public. 2021. Available online: https://www.who.int/emergencies/ diseases/novel-coronavirus-2019/advice-for-public (accessed on 2 September 2021).

6. W.H.O. The WHO Guidelines Infection Prevention and Control of Epidemic and Pandemic-Prone Acute Respiratory Infections in Health Care; WHO Press: Geneva, Switzerland, 2014. 
7. Roberge, R.J. Face shields for infection control: A review. J. Occup. Environ. Hyg. 2016, 13, 235-242. [CrossRef] [PubMed]

8. Lee, E.-H.; Lee, S.-W.; Moon, S.; Son, J. Performance Evaluation of Commercially Available Masks in Korea for Filtering Airborne Droplets Containing Bacteria. Int. J. Environ. Res. Public Health 2021, 18, 7909. [CrossRef]

9. Jeong, S.B.; Ko, H.S.; Seo, S.C.; Jung, J.H. Evaluation of filtration characteristics and microbial recovery rates of commercial filtering facepiece respirators against airborne bacterial particles. Sci. Total. Environ. 2019, 682, 729-736. [CrossRef]

10. Milton, D.K.; Fabian, M.P.; Cowling, B.; Grantham, M.L.; McDevitt, J.J. Influenza Virus Aerosols in Human Exhaled Breath: Particle Size, Culturability, and Effect of Surgical Masks. PLoS Pathog. 2013, 9, e1003205. [CrossRef] [PubMed]

11. Johnson, D.F.; Druce, J.; Birch, C.; Grayson, M.L. A Quantitative Assessment of the Efficacy of Surgical and N95 Masks to Filter Influenza Virus in Patients with Acute Influenza Infection. Clin. Infect. Dis. 2009, 49, 275-277. [CrossRef] [PubMed]

12. Kim, M.C.; Bae, S.; Kim, J.Y.; Park, S.Y.; Lim, J.S.; Sung, M.; Kim, S.H. Effectiveness of surgical, KF94, and N95 respirator masks in blocking SARS-CoV-2: A controlled comparison in 7 patients. Infect. Dis. 2020, 52, 908-912. [CrossRef]

13. W.H.O. Coronavirus Disease (COVID-19) Advice for the Public: When and How to Use Masks. 2020. Available online: https: //www.who.int/emergencies/diseases/novel-coronavirus-2019/advice-for-public/when-and-how-to-use-masks?gclid= Cj0KCQjwm9yJBhDTARIsABKIcGYyT3maOXWZ8aYahBAZ2izflp8I5pvXkY03eNiLeRaa8YCIW4Q2b30aApMyEALw_wcB (accessed on 8 September 2021).

14. Guellich, A.; Tella, E.; Ariane, M.; Grodner, C.; Nguyen-Chi, H.-N.; Mahé, E. The face mask-touching behavior during the COVID-19 pandemic: Observational study of public transportation users in the greater Paris region: The French-mask-touch study. J. Transp. Health 2021, 21, 101078. [CrossRef]

15. Chughtai, A.A.; Stelzer-Braid, S.; Rawlinson, W.; Pontivivo, G.; Wang, Q.; Pan, Y.; Zhang, D.; Zhang, Y.; Li, L.; MacIntyre, C.R. Contamination by respiratory viruses on outer surface of medical masks used by hospital healthcare workers. BMC Infect. Dis. 2019, 19, 491. [CrossRef] [PubMed]

16. Ulrich, N.; Nagler, K.; Laue, M.; Cockell, C.S.; Setlow, P.; Moeller, R. Experimental studies addressing the longevity of Bacillus subtilis spores-The first data from a 500-year experiment. PLoS ONE 2018, 13, e0208425. [CrossRef] [PubMed]

17. Chada, V.G.R.; Sanstad, E.A.; Wang, R.; Driks, A. Morphogenesis of Bacillus Spore Surfaces. J. Bacteriol. 2003, $185,6255-6261$. [CrossRef] [PubMed]

18. Cho, W.-I.; Chung, M.-S. Bacillus spores: A review of their properties and inactivation processing technologies. Food Sci. Biotechnol. 2020, 29, 1447-1461. [CrossRef]

19. Bressuire-Isoard, C.; Broussolle, V.; Carlin, F. Sporulation environment influences spore properties in Bacillus: Evidence and insights on underlying molecular and physiological mechanisms. FEMS Microbiol. Rev. 2018, 42, 614-626. [CrossRef]

20. Bin Jeong, S.; Heo, K.J.; Ko, H.S.; Ahn, J.P.; Lee, S.; Jung, J.H. Evaluation of survival rates of airborne microorganisms on the filter layers of commercial face masks. Indoor Air 2021, 31, 1134-1143. [CrossRef]

21. Lin, T.-H.; Tang, T.-H.; Chiang, C.-H.; Chang, C.-P.; Lai, C.-Y. Recovery of bacteria in filtering facepiece respirators and effects of artificial saliva/perspiration on bacterial survival and performance of respirators. Aerosol. Air Qual. Res. 2017, 17, 187-197. [CrossRef]

22. Wang, Z. Survival of Bacteria on Respirator Filters. Aerosol Sci. Technol. 1999, 30, 300-308. [CrossRef]

23. Noda, J.; Tomizawa, S.; Hoshino, B.; Munkhjargal, E.; Kawai, K.; Kai, K. Atmospheric dust as a possible survival factor for bioaerosols. E3S Web Conf. 2019, 99, 04007. [CrossRef]

24. Hara, K.; Zhang, D. Bacterial abundance and viability in long-range transported dust. Atmospheric Environ. 2012, 47, 20-25. [CrossRef]

25. Gong, J.; Qi, J.; Yin, B.E.; Gao, D. Concentration, viability and size distribution of bacteria in atmospheric bioaerosols under different types of pollution. Environ. Pollut. 2020, 257, 113485. [CrossRef] [PubMed]

26. Madhwal, S.; Prabhu, V.; Sundriyal, S.; Shridhar, V. Ambient bioaerosol distribution and associated health risks at a high traffic density junction at Dehradun city, India. Environ. Monit. Assess. 2020, 192, 196. [CrossRef] [PubMed]

27. Shammi, M.; Rahman, M.; Tareq, S.M. Distribution of Bioaerosols in Association With Particulate Matter: A Review on Emerging Public Health Threat in Asian Megacities. Front. Environ. Sci. 2021, 9, 9. [CrossRef]

28. Liu, H.; Zhang, X.; Zhang, H.; Yao, X.; Zhou, M.; Wang, J.; He, Z.; Zhang, H.; Lou, L.; Mao, W.; et al. Effect of air pollution on the total bacteria and pathogenic bacteria in different sizes of particulate matter. Environ. Pollut. 2018, 233, 483-493. [CrossRef] [PubMed]

29. Amarloei, A.; Fazlzadeh, M.; Jafari, A.J.; Zarei, A.; Mazloomi, S. Particulate matters and bioaerosols during Middle East dust storms events in Ilam, Iran. Microchem. J. 2020, 152, 104280. [CrossRef] 